\title{
Low Sperm Counts: Biophysical Profiles of Oligospermic Males in Sub-Saharan Africa
}

\author{
Abayomi B. Ajayi ${ }^{1}$, Bamgboye M. Afolabi2 ${ }^{*}$, Victor D. Ajayi ${ }^{1}$, Ifeoluwa Oyetunji ${ }^{1}$, \\ Adedamilola Atiba1 \\ ${ }^{1}$ Nordica Fertility Centre, Lagos, Nigeria \\ ${ }^{2}$ Health, Environment and Development Foundation, Lagos, Nigeria \\ Email: ^bmafolabi@gmail.com
}

How to cite this paper: Ajayi, A.B., Afolabi, B.M., Ajayi, V.D., Oyetunji, I. and Atiba, A. (2018) Low Sperm Counts: Biophysical Profiles of Oligospermic Males in Sub-Saharan Africa. Open Journal of Urology, 8, 228-247.

https://doi.org/10.4236/oju.2018.88026

Received: June 5, 2018

Accepted: August 20, 2018

Published: August 23, 2018

Copyright $\odot 2018$ by authors and Scientific Research Publishing Inc. This work is licensed under the Creative Commons Attribution International License (CC BY 4.0).

http://creativecommons.org/licenses/by/4.0/

\begin{abstract}
Introduction: Male infertility is a public health burden and a psychological dilemma in the life of the affected man. Subjects and Methods: A total of 911 men were studied retrospectively, from 2010 to 2015. Among these, 49.7\% had normal sperm count, $39.3 \%$ were oligospermic and $12.0 \%$ were azoospermic. Azoospermic men were withdrawn from this study solely to investigate the seminal fluid parameters and the biophysical characteristics of oligospermic men in contrast to those with normal sperm count. Age was stratified into $<30,30-39.9,40-49.9,50-59.9$ and $\geq 60$ years; body mass index was categorized into underweight $(<18.5)$, normal (18.5 - 24.9), overweight (25.0 - 29.9) and obese $(\geq 30)$ and standard semen analysis was performed. Results: The means ( \pm sd) of age and of BMI of the 802 subjects of the study were $42.7( \pm 7.0)$ years and $26.9(3.9) \mathrm{kg} / \mathrm{m}^{2}$ respectively. There was no significant difference in the age or BMI of normal and oligospermic men. A total of $453(56.5 \%)$ had normal sperm count while 349 (43.5\%) were oligospermic. Compared to normal weight men, those overweight and those obese were, respectively, $1.11\left(\chi^{2}=0.44, \mathrm{P}\right.$-value $\left.=0.51, \mathrm{OR}=1.11,95 \% \mathrm{CI}=0.81,1.54\right)$ and 1.56 times $\left(\chi^{2}=4.50, \mathrm{P}\right.$-value $\left.=0.03, \mathrm{OR}=1.56,95 \% \mathrm{CI}=1.03,2.36\right)$ more likely to be oligospermic. The mean of normal oval head sperms was significantly higher $(\mathrm{t}=-7.31$, P-value $=0.00001)$ in normal men $(47.8 \pm 8.9)$ than in oligospermic men $(43.0 \pm 10.7)$. Oligospermic men were over 4 times as likely to produce progressive sperm motility of $<32 \%\left(\chi^{2}=70.90, \mathrm{P}\right.$-value $=$ $0.000001, \mathrm{OR}=4.24,95 \% \mathrm{CI}=2.99,6.02)$ than men with normal sperm count. Multivariate regression analysis shows negative but significant correlations between age and semen volume (coef. $=-0.04$, Std Err. $=0.01, \mathrm{t}=-4.01$, P-value $=0.0001,95 \%$ CI: $-0.06,-0.02)$ and between BMI and sperm count (coef. $=-0.18$, Std Err. $=0.06, \mathrm{t}=-3.26, \mathrm{P}$-value $=0.001,95 \%$ CI: -0.29 , $-0.07)$. Conclusion: Our findings suggest that overweight and obesity are
\end{abstract}


associated with oligospermia and oligospermia is significantly linked with low progressive motility, and various sperm cell defects.

\section{Keywords}

Oligospermia, Age, Body Mass Index, Male Infertility, Sperm Cell Defects, Sub-Saharan Africa

\section{Introduction}

Infertility and problems of impaired fecundity have been a concern through ages [1]. As a disease of the reproductive system, it is defined as failure to achieve clinical pregnancy after 12 months or more of regular unprotected sexual intercourse [2]. Incidentally, the first study of the epidemiology of infertility was published in Scotland in 1866 by Matthews Duncan whose book, Fecundity, Fertility and Sterility, [3] was the first, and until recently the only, population-based study of infertility [4]. It is regrettable that extremely few national data on the prevalence of infertility exists, especially in Africa where voluntary infertility is an anathema, though not in developed countries. A good example of voluntary infertility occurred in the US in the first 3 decades of the last century, though it became less common thereafter only to surface again in the 1960s [5]. Globally, there has been a measure of difficulties in assessing the prevalence of infertility due to rarity of large-scale surveys on this subject [6] [7] except the US National Survey of Family Growth (NSFG) [8].

Infertility is estimated to affect as many as 186 million people worldwide. Although male infertility contributes to more than half of all cases of global childlessness, infertility remains a woman's social burden [9]. In recent times, infertility has become a significant clinical problem affecting $8 \%-12 \%$ of couples worldwide [1]. Male factor is responsible for about $40 \%-50 \%$ cases of infertility in couples who desire to have children and it is estimated that approximately $2 \%$ of men with male factor infertility have sub-optimal sperm parameters such as 1) low sperm concentration 2) poor sperm motility and 3) abnormal morphology [1]. The high prevalence of infectious diseases in less developing countries may be responsible for high rate of infertility in these parts of the globe. Low "sperm concentration" or "sperm count" referred to as Oligospermia, is a male fertility issue defined as a low sperm concentration in the ejaculate (typically milliliters or $\mathrm{mL}$ ). As defined by the World Health Organization (WHO) in 2000, oligospermia is low sperm countless than 15 million sperm/mL [10]. The exact global prevalence of oligospermia is not known though studies have indicated regional variations in the mean sperm concentration among men in USA and France [11] [12] [13] [14]. Also, geographic, ethnic, climatic and occupational factors have been suggested to be responsible for the regional differences in the sperm counts in men [13] [14] [15]. Isolated studies show higher prevalence of oligospermia 
among Caucasians [16]. The prevalence of oligospermia was $22.9 \%$ in Pakistan [17], 15.6\% in Tanzania [18], 25.6\% in South-west and Ile-Ife [19] and 35.9\% in South-east Nigeria [20]. A study in Ghana reported that "half of the respondents had very low sperm counts (oligospermia)" [21]. The cause of oligospermia may be multifactorial, including chromosomal mutations-translocations, inversions, deletions, as well as structural and numerical abnormalities [22], microdeletions of AZF on the Y chromosome and CFTR mutations. It is estimated that more than $75 \%$ of infertile males have an underlying chromosomal error [23]; infections such as viral orchitis, caused by mumpsvirus, hepatitis and human immunodeficiency virus (HIV) infection; endocrine disorders affecting the hypothalamic-pituitary-gonadal axis such as hypogonadism, hypothyroidism, hyperprolactinemia (usually as a result of a pituitary prolactinoma), acromegaly and adrenal hyperplasia; iatrogenic causes, such as drugs which interfere with spermatogenesis, including chemotherapeutic agents, sulfasalazine, corticosteroids, estrogens, antimalarials, nicotine, cimetidine, ethanol, opioids, methotrexate and many other [24]; testicular and endocrine tumors, as well as trauma with subsequent orchidectomy [25]. Clinical evaluation of male fertility begins with a detailed history and physical examination, which generally will provide valuable information to guide what additional laboratory investigations or imaging studies to complete the evaluation. The two main purposes of male infertility evaluation are 1) to identify any modifiable factors that can improve the fertility status of the man and 2) to identify any underlying serious condition(s) such as testis cancer, osteoporisis, endocrinological and genetic problems that present first as infertility. Semen analysis remains the single most useful and fundamental investigation with a sensitivity of $89.6 \%$, that it can detect 9 out of 10 men with a genuine problem of male infertility [26]. There is paucity of information on the biophysical characteristics of patients with oligospermia in sub-Saharan Africa which makes this the objective of this study among infertile males who present for Assisted Reproduction Technology (ART) in Nigeria.

\section{Subjects and Methods}

This has been described elsewhere [27]. In summary, between 2010 and 2015, 916 men, aged between 23 and 73 years, consulted for infertility at the offices of Nordica Fertility Center (NFC) in three Nigerian cities-Lagos, Abuja and Asaba respectively. Among them, 607 (66.3\%) were couples while (309, 33.7\%) consulted alone. At first consultation, all the patients were counselled on the need for various laboratory analyses, especially seminal fluid analysis (SFA) for the male partners and other necessary investigations for each couple spouses to ascertain the exact cause(s) of infertility. In all, 907 (99.0\%) of the 916 responded correctly to the counselling and produced semen for SFA. Various reasons were given by the remaining 9 men for not producing seminal fluid, such as 1) travelled out $(4,44.4 \%) 2$ ) coincided with fasting period $(2,22.2 \%)$ and 3$)$ absconded $(2,22.2 \%)$ and 4$)$ specimen was discarded due to improper collection 
(1, 11.1\%). The data of all those who produced seminal fluid for analysis, in strict compliance with World Health Organization's (WHO) instruction for SFA [10] were analyzed. All the sampled patients consulted because their spouses or partners were not getting pregnant despite uninterrupted, regular and constant unprotected sexual intercourse.

Subjects' ages (years) were categorized into $\leq 30,30.1$ - 35, 35.1 - 40, 40.1 - 45, 45.1 - 50 and >50, BMI into <18.5 (underweight), 18.5 - 24.5 (normal), 25.0 29.9 (overweight) and $\geq 30$ (obese) extracted from medical records who presented because of infertility at three Nigerian cities-Lagos, Asaba and Abuja were retrieved, entered into a laptop computer, cleaned and analyzed. Semen samples were obtained by masturbation and collected in a sterile, nontoxic plastic wide-mouth container. The sample was transported to the clinical laboratory within a maximum of 3 - 5 minutes' walk to according to WHO guidelines [22]. The patient was counseled to abstain from sex for minimum/maximum duration of 2 - 5 days and importance of abstinence time was explained. Patients were given clear and simple instructions on the following: 1) accuracy in the semen collection, 2) semen should be collected in a wide-mouth measuring cylinder that was provided, and 3) the importance of reporting any loss of semen sample during collection. For this semen collection process, each patient was provided with a medical record form where data such as name, age (or date of birth), days of abstinence, date and time of collection, if there was any loss in semen volume during collection (incomplete collection) and the time of commencement of seminal fluid analysis in the laboratory were appropriately filled in by the patient and the laboratory staff who collected the semen samples.

At the point of first contact each patient was weighed $(\mathrm{kg})$ and had his height measured $(\mathrm{cm})$ for BMI determination and each patient's medical, surgical, family and social history were taken, including marital status, occupation, smoking and alcohol use. Past histories of groin operation, sexually transmitted diseases and varicocelectomy were taken. Medical data of these patients were managed by retrieval, entered into Excel spreadsheet on a laptop computer, cleaned and analyzed. WHO specification was strictly followed in the analysis of the two semen samples collected by masturbation per patient. Prior to sample collection, the patients were counselled on the need to observe accuracy in semen collection into a wide-mouth measuring cylinder provided to each patient and any loss of semen sample during production and collection into the measuring cylinder should be reported. Thus, all patients were given a special wide-mouth calibrated cylinder in which to collect the seminal fluid; semen samples were collected, as sterile as possible, by the process of masturbation and submitted to the laboratory within 30 minutes of collection; and all patients were advised to not have sexual intercourse for a minimum of 2 days and a maximum of 5 days. In addition, each patient was given a specific record form where data demographic data, number of days of abstinence, date and time of collection, any loss in semen volume during collection and the time of commencement of SFA in the laboratory 
were appropriately filled in by the patient and the laboratory staff who collected the semen samples.

All semen samples were delivered to the laboratory on time and after liquefaction has taken place, the samples were analyzed for volume, total sperm concentration, motility, and morphology strictly according to WHO guidelines [10]. Sperm morphology is not reported in this paper. Semen volume was measured by directly from the meniscus of calibrated wide-mouth measuring cylinder given to each patient. Light microscope ( $\times 40$ magnification) with eyepiece reticle having grid was used to determine 1) mean progressive motion-a) rapid forward, fast progressive motility, b) moderately forward, slow progressive motility, c) jerky non-progressive motility and d) immotile/no movement 2) sperm concentration-counting at least 200 spermatozoa and expressing these as $10^{6}$ spermatozoa/ml, in a 3 - $5 \mu \mathrm{L}$ of semen sample transferred to the center of the Neubauer Chamber and 3) progressive motion-categorized into $\geq 32 \%$ or $<32 \%$. Other parameters assessed in each semen sample were color, viscosity and liquefaction time. Age (years) was classified into <30, 30 - 39.9, 40 - 49.9, 50 - 59.9 and $\geq 60$ and BMI $\left(\mathrm{kg} / \mathrm{m}^{2}\right)$ into underweight (BMI $<18.5$ ), normal weight (BMI 18.5 - 24.9), overweight (BMI 25.0 - 29.9) and obese (BMI $\geq 30$ ) according to the conventional WHO classification [28]. Patients who were not on any medication that would interfere with spermatogenesis, those not consuming herbal medication and who gave consent for their semen to be analyzed were included into the study. Patients initially screened out of this study were those who earlier gave a medical history of i) chronic liver disease, ii) renal failure, iii) HIV infection, iv) diabetes mellitus or v) tuberculosis of the genitourinary system, vi) urethral disease or those who gave surgical history of i) undescended testis or ii) operations on the testis. Further analysis of the data specifically focused on men with normal sperm count and those with oligospermia.

Data were analyzed using STATA 13; associations between Age, BMI and Age-for-BMI with normal sperm concentration and with oligospermia were assessed using chi-square, Odds ratio and 95\% Confidence Interval. Spearman correlation and analysis of variance (ANOVA), and a multiple linear regression analysis were performed to determine correlation coefficients and significance of means of two variables. In addition, the relative risks for men having oligospermia, giving reference range of the WHO [10], were calculated. A P-value of $\leq 0.05$ was taken as significant. Data were presented as Tables and bar charts.

\section{Results}

The total number of participants in this study was initially 911 among whom 453 (49.7\%) had normal sperm count, 109 (12.0\%) were azoospermic and 349 (38.3\%) were oligospermic, according to WHO classification [10]. For the purpose of this study, all the azoospermic patients were excluded, leaving 802 males whose means ( \pm sd) of age (years) and BMI $\left(\mathrm{kg} / \mathrm{m}^{2}\right)$ were 42.7 (7.0) and 26.9 (3.9) respectively, for further analysis. The main reason for the exclusion of the 
azoospermic patients was sole to study the biophysical characteristics of oligospermic patients relative to those with normal sperm count. Further, azoospermia from this same group of patients has been studied and reported earlier [27]. The highest proportion $(396,49.4 \%)$ of patients were in the age group of $40-49$ years, while the least were those aged $\geq 60$ years $(10,1.2 \%)$. Only $4(0.5 \%)$ were classified as underweight while 245 (30.5\%), 408 (50.9\%) and 145 (18.2\%) were categorized as normal weight, overweight and obese respectively. In all, 349 (43.5\%) of the 802 men were oligospermic, the majority of whom were aged 40 49.9 years $(172,44.0 \%)$, or overweight $(174,49.9 \%)$. The remaining 453 (56.5\%) had normal sperm count. There was no significant difference in the means of age and of BMI of men with normal sperm (count $42.6 \pm 7.0$ years; $26.8 \pm 4.0 \mathrm{~kg} / \mathrm{m}^{2}$ respectively) and those with oligospermia (42.8 \pm 7.2 years; $27.1 \pm 3.7 \mathrm{~kg} / \mathrm{m}^{2}$ respectively) (Table 1).

There was no significant difference in the overall mean seminal fluid volume (SFV) (ml.) of those with normal sperm count $(2.3 \pm 1.6)$ and those with oligospermia $(2.2 \pm 1.3)$. However, when segregated by age, significant disparity (t-test $=$ 2.86, P-value $=0.002)$ was observed only in the mean SFV (ml.) of normal $(2.4 \pm$ $2.4)$ and oligospermic $(1.5 \pm 0.8)$ men aged $50-59$ years. When segregated by $\mathrm{BMI}$, noteworthy difference $(\mathrm{t}$-test $=2.09, \mathrm{P}$-value $=0.02)$ was observed only in the mean SFV (ml.) of normal $(2.4 \pm 1.7)$ and oligospermic $(2.1 \pm 1.2)$ men who were overweight (Table 2). The Table also shows that, as expected, the mean sperm count $\left(\times 10^{6} / \mathrm{ml}\right)$ of normal men $(40.4 \pm 19.8)$ was significantly higher $(\mathrm{t}=$ 103.61, P-value $=0.000001)$ than that of men with oligospermia $(5.6 \pm 3.9)$. This was evident in all categories of age and of BMI. Although, the difference in overall liquefaction time (mins.) of normal men $(30.8 \pm 8.8)$ and of oligospermic men $(30.9 \pm 8.0)$ was insignificant, it was not until this variable was examined closely in segregated age that it became clear that liquefaction time (mins.) was

Table 1. Demographic characteristics of study participants relevant to their sperm count status.

\begin{tabular}{|c|c|c|c|c|c|c|c|c|}
\hline \multirow{3}{*}{ Variable } & \multirow{3}{*}{ Item } & \multirow{2}{*}{\multicolumn{2}{|c|}{ All patients }} & \multicolumn{4}{|c|}{ Category of patient } & \multirow{3}{*}{ t-test (P-value) } \\
\hline & & & & \multicolumn{2}{|c|}{ Normal sperm count } & \multicolumn{2}{|c|}{ Low sperm count } & \\
\hline & & Total (\%) & Mean $( \pm$ sd) & $\mathrm{n}$ & Mean $( \pm$ sd) & $\mathrm{n}$ & Mean ( \pm sd) & \\
\hline \multirow[t]{3}{*}{ All } & Age & $802(100.0)$ & $42.7(7.0)$ & 453 & $42.6(7.0)$ & 349 & $42.8(7.2)$ & not significant \\
\hline & $<30$ & $11(1.4)$ & $27.6(1.6)$ & 4 & $26.5(2.6)$ & 7 & $28.1(0.7)$ & not significant \\
\hline & $30-39$ & $263(32.8)$ & $35.7(2.6)$ & 153 & $35.7(2.5)$ & 110 & $35.7(2.6)$ & not significant \\
\hline \multirow[t]{5}{*}{ Age groups (years) } & $40-49$ & $396(49.4)$ & $44.0(2.9)$ & 224 & $44.0(2.9)$ & 172 & $44.0(3.0)$ & not significant \\
\hline & $50-59$ & $122(15.2)$ & $53.1(2.6)$ & 66 & $52.9(2.5)$ & 56 & $53.2(2.7)$ & not significant \\
\hline & $\geq 60$ & $10(1.2)$ & $63.9(4.2)$ & 6 & $64.2(2.8)$ & 4 & $63.5(6.3)$ & not significant \\
\hline & BMI & $802(100.0)$ & $26.9(3.9)$ & 453 & $26.8(4.0)$ & 349 & $27.1(3.7)$ & not significant \\
\hline & $<18.5$ & $4(0.5)$ & $18.1(0.9)$ & 1 & $18.5(0.0)$ & 3 & $17.9(1.0)$ & - \\
\hline \multirow[t]{3}{*}{$\begin{array}{l}\text { Body Mass Index } \\
\qquad\left(\mathrm{kg} / \mathrm{m}^{2}\right)\end{array}$} & $18.5-24.9$ & $245(30.5)$ & $23.2(1.3)$ & 147 & $23.2(1.4)$ & 98 & $23.2(1.3)$ & not significant \\
\hline & $25.0-29.9$ & $408(50.9)$ & $27.1(1.3)$ & 234 & $27.2(1.3)$ & 174 & $27.1(1.3)$ & not significant \\
\hline & $\geq 30$ & $145(18.2)$ & $32.8(3.8)$ & 71 & $33.2(4.9)$ & 74 & $32.5(2.3)$ & not significant \\
\hline
\end{tabular}


Table 2. Means of semen volume, sperm concentration and liquefaction time by age and by BMI of normal and oligospermic males.

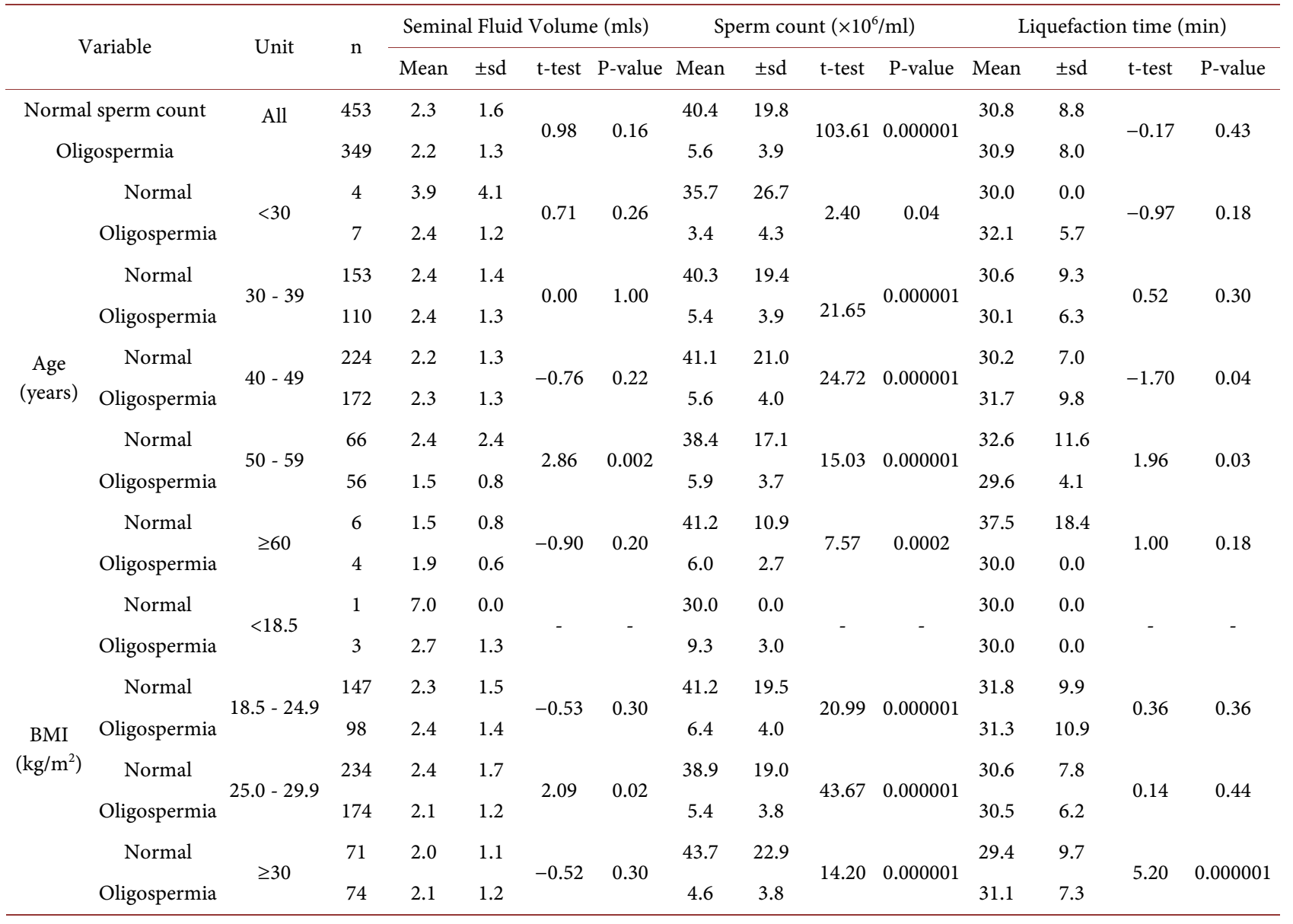

significantly shorter $(\mathrm{t}=-1.70, \mathrm{P}$-value $=0.04)$ in normal men aged $40-49$ years $(30.2 \pm 7.0)$ compared to oligospermic men $(31.7 \pm 9.8)$ in the same age group, and significantly shorter $(\mathrm{t}=1.96, \mathrm{P}$-value $=0.03)$ in normal men aged $50-59$ years $(32.6 \pm 9.8)$ compared to oligospermic men in the same age group $(29.6 \pm$ 4.1). In the same vein, liquefaction time (mins.) of obese men with normal sperm count $(29.4 \pm 9.7)$ was significantly lower $(t=5.20, P$-value $=0.000001)$ than that of obese men who were oligospermic $(31.1 \pm 7.3)$.

In all, $191(23.8 \%)$ of the 802 participants produced seminal fluid $<1.5 \mathrm{ml}$, (considered to be abnormal by WHO standard [10]) among whom none was aged $<30$ years, $51(26.7 \%)$ were aged 30 - 39 years, 90 (47.1\%) were aged 40 - 49 years, $46(24.1 \%)$ were between 50 - 59 years of age and only 4 (2.1) were aged 60 years or more. A total of 107 (56.0\%) from the 191 men had normal sperm count while 84 (44.0\%) were oligospermic. Among the 107, 31 (60.8\%), 52 (57.8\%), 21 (45.6\%) and 3 (75.0\%) were aged $30-39,40-49,50-59$ and $\geq 60$ years respectively. The remaining 84 were oligospermic, among whom $20(39.2 \%), 38$ (42.2\%), 25 (54.3\%) and 1 (25.0\%) were aged $30-39,40-49,50-59$ and $\geq 60$ years respectively (Figure $1(\mathrm{a})$ ). The Figures indicates that as age group increases the proportion of normal men who produced seminal fluid $<1.5 \mathrm{ml}$ increases 


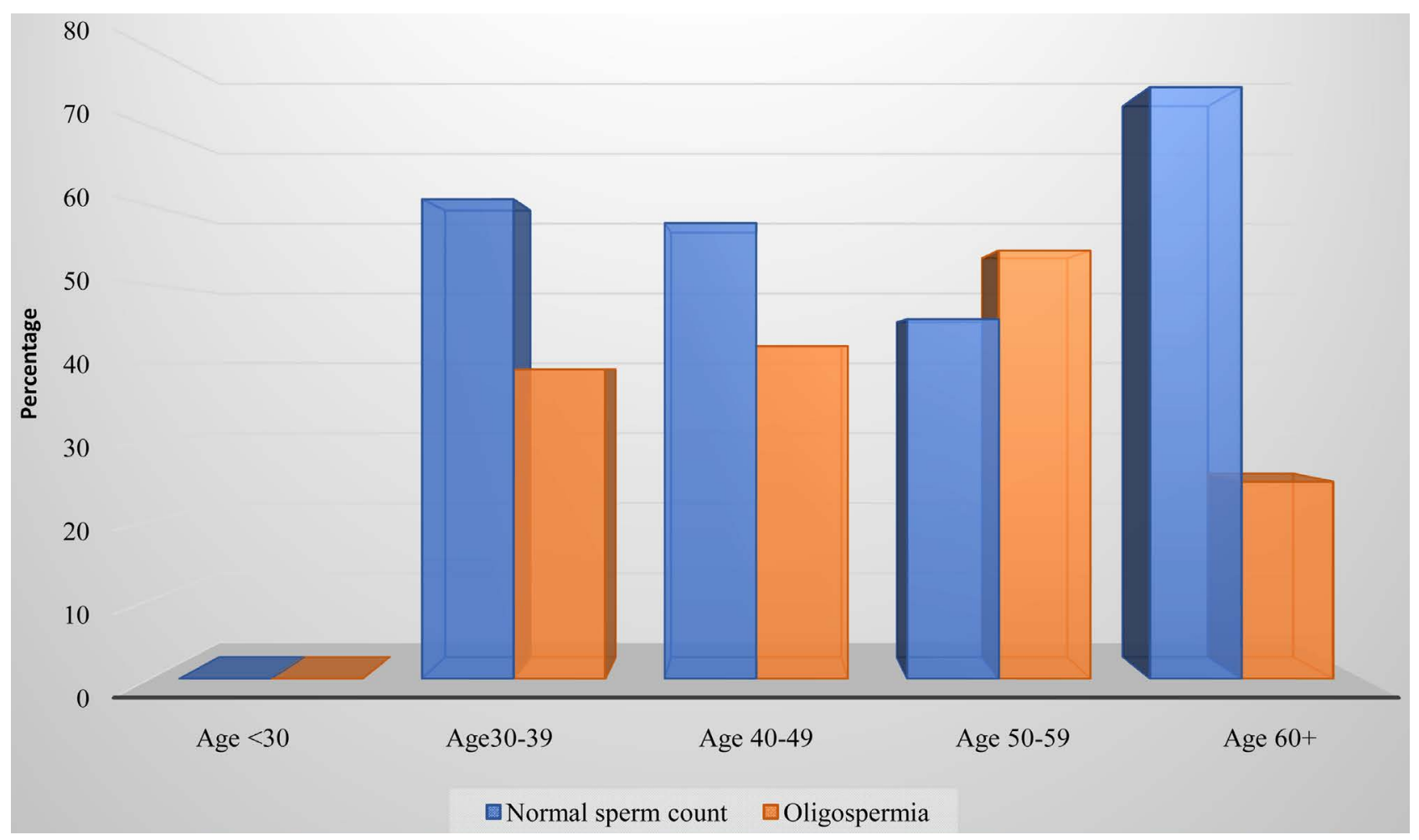

Figure 1. Age distribution of normal and oligospermic patients who produced seminal fluid $<1.5 \mathrm{ml}$.

while that of oligospermic men increases, barring those aged $\geq 60$ years.

Figure 2 shows that, among oligospermic patients, overweight (44/91, 48.4\%), not obese(19/40,47.5\%), was the major contributor to the production of seminal fluid $<1.5 \mathrm{ml}$, whereas inpatients with normal sperm count, normal weigh contributed more to the production of seminal fluid $<1.5 \mathrm{ml}$, than overweight or obese.

The frequency distribution of Progressive Motility (PM) among men with normal and oligospermic men is as depicted in Table 3. Using WHO standard [10], 192 (23.9\%) patients had PM of <32\% of whom 134 (69.8\%) were oligospermic and only 58 (30.2\%) had normal sperm count while 610 (76.1\%) had PM of $>32 \%$ of whom 215 (35.3\%) were oligospermic and 395 (64.7\%) had normal sperm count. Oligospermic patients were over 4 times more likely to have progressive motion of $<32 \%$ than normal sperm patients $\left(\chi^{2}=70.90\right.$, P-value $=$ $0.000001, \mathrm{OR}=4.24,95 \% \mathrm{CI}=2.99,6.02)$ and the risk of low progressive motility was 1.98 among oligospermic patients compared to normal patients. Patients aged $40-49$ years $(63,47.0 \% ; 195,49.4 \%)$ were the highest proportion of oligospermic patients with $\mathrm{PM}$ of $<32 \%$ and of $\geq 32 \%$ respectively while overweight men $(69,51.5 \% ; 204,51.6 \%)$ were the highest proportion of oligospermic patients with $\mathrm{PM}$ of $<32 \%$ and of $\geq 32 \%$ respectively. Oligospermic patients aged 30 39 years were 7.4 times more likely to develop low sperm motility compare to patients with normal sperm count in the same age group $\left(\chi^{2}=40.50\right.$; $\mathrm{P}$-value $=$ 0.00001; $\mathrm{OR}=7.4 ; 95 \% \mathrm{CI}=3.80,14.43)$. Also, oligospermic patients aged 30 49 years $\left(\chi^{2}=30.59 ; \mathrm{P}\right.$-value $\left.=0.00001 ; \mathrm{OR}=3.9 ; 95 \% \mathrm{CI}=2.36,6.40\right)$. And those 


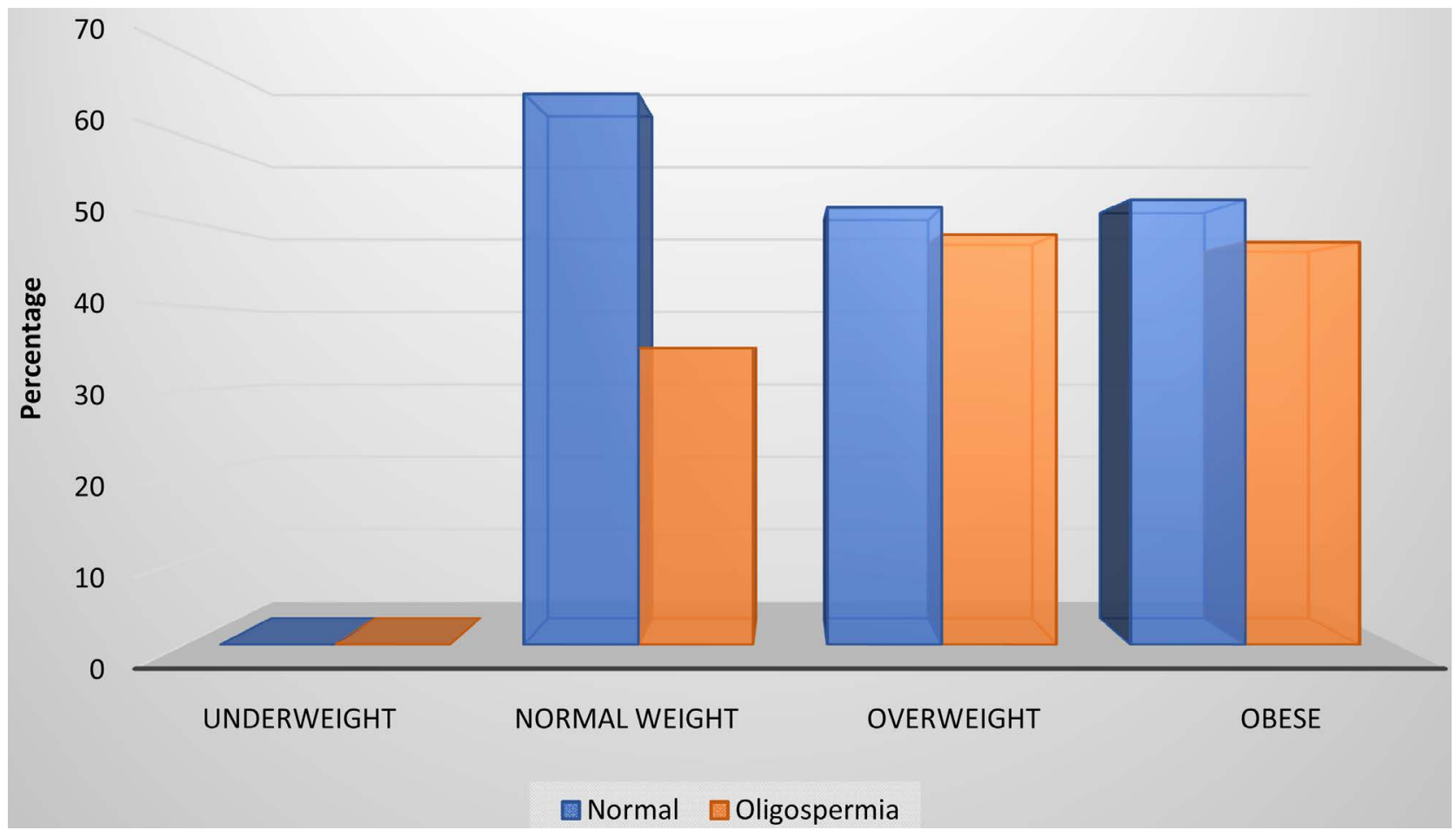

Figure 2. BMI distribution of normal and oligospermic men who produced semen volume $<1.5 \mathrm{ml}$.

aged $50-59$ years $\left(\chi^{2}=0.91 ; \mathrm{P}\right.$-value $\left.=0.34 ; \mathrm{OR}=1.48 ; 95 \% \mathrm{CI}=0.66,3.33\right)$ were only 3.89 and 1.48 times as likely to have low progressive motility compare to patients with normal sperm count in the same age group (data not shown).

Table 4 and Figure 3 show the frequency distribution of mean Progressive motion in the two groups of patients. Surprisingly, a significantly higher $\left(\chi^{2}=\right.$ $22.13 ; \mathrm{P}$-value $=0.000004 ; \mathrm{OR}=0.40 ; 95 \% \mathrm{CI}=0.27,0.59)$ proportion of normal men $(113,24.9 \%)$ presented with poor MPM compared with oligospermic men (41, 11.7\%). Similarly, the proportion of normal men who presented with fair $\operatorname{MPM}(239,52.8 \%)$ was significantly higher $\left(\chi^{2}=59.44 ; \mathrm{P}\right.$-value $=0.000001 ; \mathrm{OR}=$ 3.38 ; $95 \% \mathrm{CI}=2.46,4.65)$ compared to oligospermic men $(276,79.1 \%)$ who presented with fair MPM. However, the proportion of men with normal sperm count who presented with good MPM was significantly higher than that of oligospermic men who were not as likely to produce good MPM as men with normal sperm count $\left(\chi^{2}=25.79 ; \mathrm{P}\right.$-value $=0.000001 ; \mathrm{OR}=0.34 ; 95 \% \mathrm{CI}=0.22$, 0.52). The Table also shows that a large proportion of overweight oligospermic patients presented with poor $(20,48.8 \%)$, fair $(135,48.9 \%)$ or $\operatorname{good}(18,58.1 \%)$ MPM while a lesser proportion of obese oligospermic patients presented with poor $(12,29.3 \%)$, fair $(54,19.6 \%)$ and good (8, 25.8\%) MPM. Obese oligospermic patients were only 1.20 times $\left(\chi^{2}=0.20 ; \mathrm{P}\right.$-value $=0.65 ; \mathrm{OR}=1.20 ; 95 \% \mathrm{CI}=$ $0.54,2.65), 2.49$ times $\left(\chi^{2}=13.84 ; \mathrm{P}\right.$-value $=0.0002 ; \mathrm{OR}=2.49 ; 95 \% \mathrm{CI}=1.52$, 4.06) and 2.35 times $\left(\chi^{2}=3.00 ; \mathrm{P}\right.$-value $\left.=0.09 ; \mathrm{OR}=2.35 ; 95 \% \mathrm{CI}=0.87,6.36\right)$ more likely to have poor, fair or good MPM than obese men with normal sperm count. 
Table 3. Frequency distribution of Progressive Motility in normal and oligospermic patients.

\begin{tabular}{|c|c|c|c|c|c|c|}
\hline \multirow{4}{*}{ Variable } & \multirow{4}{*}{ Category } & \multirow{4}{*}{ Statistics } & \multicolumn{4}{|c|}{ Progressive Motility (\%) } \\
\hline & & & \multicolumn{2}{|c|}{$<32(\mathrm{n}=192)$} & \multicolumn{2}{|c|}{$\geq 32(\mathrm{n}=610)$} \\
\hline & & & Normal & Oligospermia & Normal & Oligospermia \\
\hline & & & Freq. (\%) & Freq. (\%) & Freq. (\%) & Freq. (\%) \\
\hline & & All & $58(30.2)$ & $134(69.8)$ & $395(64.7)$ & $215(35.3)$ \\
\hline & & $\chi^{2}$ (P-value) & & 70. & 0001) & \\
\hline & & OR $(95 \% \mathrm{CI})$ & & & $6.02)$ & \\
\hline & & RR $(95 \%$ CI $)$ & & & 2.28) & \\
\hline \multirow{10}{*}{$\begin{array}{c}\text { Age } \\
\text { (years) }\end{array}$} & \multirow{2}{*}{$<30$} & Number (\%) & $0(0.0)$ & $4(3.0)$ & $4(1.0)$ & $3(1.4)$ \\
\hline & & $\chi^{2}$ (P-value)/OR $(95 \% \mathrm{CI}) / \mathrm{RR}(95 \% \mathrm{CI})$ & \multicolumn{4}{|c|}{$3.59(0.06) / 0.0$ (undefined)/2.33 $(0.99,5.49)$} \\
\hline & \multirow{2}{*}{$30-39$} & Number (\%) & $14(24.1)$ & $47(35.1)$ & $139(35.2)$ & $63(29.3)$ \\
\hline & & $\chi^{2}$ (P-value)/OR (95\% CI)/RR (95\% CI) & \multicolumn{4}{|c|}{$40.50(0.00001) / 7.40(3.80,14.43) / 2.47(1.33,3.16)$} \\
\hline & \multirow{2}{*}{$40-49$} & Number (\%) & $29(50.0)$ & $63(47.0)$ & $195(49.4)$ & $109(50.7)$ \\
\hline & & $\chi^{2}$ (P-value)/OR (95\% CI)/RR (95\% CI) & \multicolumn{4}{|c|}{$30.59(0.00001) / 3.89(2.36,6.40) / 1.91(1.56,2.34)$} \\
\hline & \multirow{2}{*}{$50-59$} & Number (\%) & $15(25.9)$ & $17(12.7)$ & $51(12.9)$ & $39(18.1)$ \\
\hline & & $\chi^{2}$ (P-value)/OR (95\% CI)/RR (95\% CI) & \multicolumn{4}{|c|}{$0.91(0.34) / 1.48(0.66,3.33) / 1.23(0.82,1.83)$} \\
\hline & \multirow{2}{*}{$\geq 60$} & Number (\%) & $0(0.0)$ & $3(2.2)$ & $6(1.5)$ & $1(0.5)$ \\
\hline & & $\chi^{2}$ (P-value)/OR (95\% CI)/RR (95\% CI) & \multicolumn{4}{|c|}{3.35 (0.07) Fisher's exact test/Undefined/7.00 $(1.14,42.97)$} \\
\hline \multirow{8}{*}{$\begin{array}{c}\text { BMI } \\
\left(\mathrm{kg} / \mathrm{m}^{2}\right)\end{array}$} & \multirow{2}{*}{$<18.5$} & Number (\%) & $0(0.0)$ & $0(0.0)$ & $1(0.2)$ & $3(1.4)$ \\
\hline & & $\chi^{2}$ (P-value)/OR (95\% CI)/RR (95\% CI) & \multicolumn{4}{|c|}{3.35 (0.07) Fisher's exact test/Undefined/7.00 $(1.14,42.97)$} \\
\hline & \multirow{2}{*}{$18.5-24.9$} & Number (\%) & $17(29.3)$ & $32(23.9)$ & $130(32.9)$ & $66(30.7)$ \\
\hline & & $\chi^{2}$ (P-value)/OR (95\% CI)/RR (95\% CI) & \multicolumn{4}{|c|}{$16.34(0.00005) / 3.70(1.92,7.16) / 1.94(1.46,2.57)$} \\
\hline & \multirow{2}{*}{$25.0-29.9$} & Number (\%) & $30(51.7)$ & $69(51.5)$ & $204(51.6)$ & $105(48.8)$ \\
\hline & & $\chi^{2}(\mathrm{P}$-value $) / \mathrm{OR}(95 \% \mathrm{CI}) / \mathrm{RR}(95 \% \mathrm{CI})$ & \multicolumn{4}{|c|}{$39.10(0.000001) / 4.47(2.74,7.29) / 2.05(1.67,2.51)$} \\
\hline & \multirow{2}{*}{$\geq 30$} & Number (\%) & $11(19.0)$ & $33(24.6)$ & $60(15.2)$ & $41(19.1)$ \\
\hline & & $\chi^{2}$ (P-value)/OR (95\% CI)/RR (95\% CI) & \multicolumn{4}{|c|}{$14.52(0.0001) / 4.39(1.99,9.67) / 1.85(1.38,2.47)$} \\
\hline
\end{tabular}

* = Relative risk (95\% Confidence Interval).

Table 5 illustrates the differences in sperm morphology observed among men with normal sperm count and those with oligospermia. The overall means ( \pm sd) of small tapering head defect (32.1 \pm 9.1$)$, double amorphous head defect $(8.2 \pm$ 8.1), Midpiece defect $(6.3 \pm 4.3)$ and tail defect $(5.1 \pm 1.1)$ in oligospermic men were significantly higher $(\mathrm{t}=3.96, \mathrm{P}$-value $=0.00001 ; \mathrm{t}=4.20, \mathrm{P}$-value $=$ $0.00001 ; \mathrm{t}=3.12, \mathrm{P}$-value $=0.0009$ and $\mathrm{t}=1.81, \mathrm{P}$-value $=0.04$ respectively) than in men with normal sperm count $(29.9 \pm 7.4 ; 6.4 \pm 5.0 ; 5.6 \pm 2.5$ and $5.0 \pm 0.6$ respectively). The observed substantial variance in mean of small tapering head defect among those with normal sperm count and those with oligospermia seemed to be driven mainly by age group $30-39$ years $(\mathrm{t}=-3.30$, P-value $=$ $0.0006)$ and by normal weight $(\mathrm{t}=-2.98, \mathrm{P}$-value $=0.002)$; that in mean of double amorphous head defect driven mainly by age group $40-49$ years $(\mathrm{t}=$ $-3.99, \mathrm{P}$-value $=0.00001)$ and by overweight $(\mathrm{t}=-4.35$, P-value $=0.00001)$; that 
Table 4. Frequency distribution of mean Progressive motion in normal and oligospermic patients.

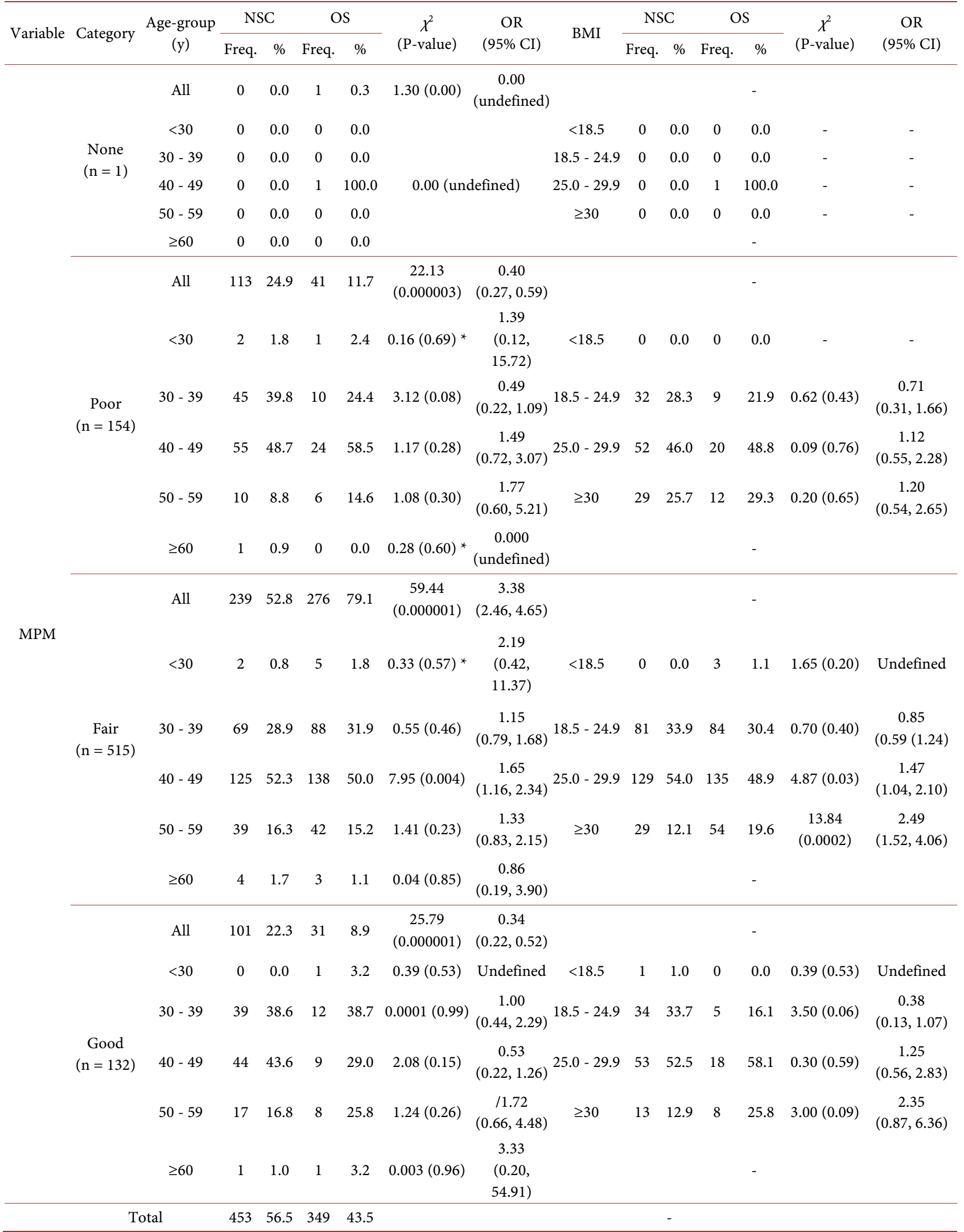

NSC $=$ Normal sperm concentration; OS = Oligospermia. 
Table 5. Sperm morphology in normal and oligospermic patients relative to age and BMI.

\begin{tabular}{|c|c|c|c|c|c|c|c|c|c|}
\hline \multirow{3}{*}{ Category } & \multirow{3}{*}{ Variable } & \multirow{3}{*}{ Item } & \multirow{3}{*}{ Total } & \multicolumn{6}{|c|}{ Sperm morphology } \\
\hline & & & & $\begin{array}{c}\text { Small tapering } \\
\text { head defect }\end{array}$ & Oval head & $\begin{array}{c}\text { Double } \\
\text { amorphous head }\end{array}$ & $\begin{array}{l}\text { Midpiece } \\
\text { defect }\end{array}$ & Tail defect & Immature form \\
\hline & & & & Mean ( $\pm s d)$ & Mean $( \pm$ sd) & Mean $( \pm s d)$ & Mean $( \pm s d)$ & Mean $( \pm s d)$ & Mean $( \pm s d)$ \\
\hline \multirow{9}{*}{ 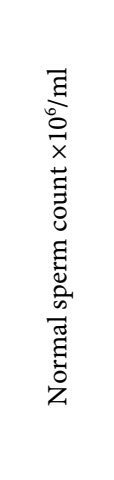 } & \multirow{5}{*}{ Age } & $<30$ & 4 & $27.5(5.0)$ & $50.0(8.1)$ & $7.5(5.0)$ & $5.0(0.0)$ & $5.0(0.0)$ & $5.0(0.0)$ \\
\hline & & $30-39$ & 153 & $30.4(7.8)$ & $48.2(9.0)$ & $6.2(6.9)$ & $5.4(2.6)$ & $5.1(0.6)$ & $5.1(0.8)$ \\
\hline & & $40-49$ & 224 & $30.9(8.3)$ & $47.1(8.9)$ & $6.2(4.6)$ & $5.5(2.3)$ & $5.0(0.6)$ & $5.2(1.5)$ \\
\hline & & $50-59$ & 66 & $30.6(7.0)$ & $46.4(9.0)$ & $6.3(3.9)$ & $5.8(2.6)$ & $5.0(0.0)$ & $5.4(2.6)$ \\
\hline & & $\geq 60$ & 6 & $34.2(4.9)$ & $43.3(8.2)$ & $7.5(6.1)$ & $5.0(0.0)$ & $5.0(0.0)$ & $5.0(0.0)$ \\
\hline & \multirow{4}{*}{ BMI } & $<18.5$ & 1 & $40.0(0.0)$ & $40.0(0.0)$ & $5.0(0.0)$ & $5.0(0.0)$ & $5.0(0.0)$ & $5.0(0.0)$ \\
\hline & & $18.5-24.9$ & 147 & $30.2(7.3)$ & $47.9(8.6)$ & $6.4(5.5)$ & $5.4(1.8)$ & $5.0(0.7)$ & $5.3(1.9)$ \\
\hline & & $25.0-29.9$ & 234 & $31.1(8.1)$ & $46.9(9.1)$ & $6.3(5.0)$ & $5.6(2.4)$ & $5.0(0.5)$ & $5.2(1.5)$ \\
\hline & & $\geq 30$ & 71 & $30.6(8.4)$ & $47.9(9.2)$ & $5.8(3.7)$ & $5.8(3.3)$ & $5.0(0.0)$ & $5.0(0.0)$ \\
\hline \multirow{9}{*}{ 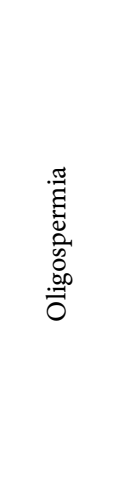 } & \multirow{5}{*}{ Age } & $<30$ & 7 & $24.3(7.9)$ & $48.6(9.0)$ & $11.4(9.4)$ & $5.0(0.0)$ & $5.7(1.9)$ & $5.0(0.0)$ \\
\hline & & $30-39$ & 110 & $34.1(9.7)$ & $40.7(10.6)$ & $8.1(7.7)$ & $7.0(6.2)$ & $5.1(1.1)$ & $5.3(2.1)$ \\
\hline & & $40-49$ & 172 & $31.0(8.8)$ & $42.5(11.4)$ & $9.4(9.7)$ & $6.2(3.8)$ & $5.1(1.1)$ & $5.7(5.1)$ \\
\hline & & $50-59$ & 56 & $29.9(7.9)$ & $44.4(10.3)$ & $8.3(6.9)$ & $6.6(4.4)$ & $5.4(1.3)$ & $5.4(2.4)$ \\
\hline & & $\geq 60$ & 4 & $27.5(9.6)$ & $45.0(10.0)$ & $8.7(7.5)$ & $8.7(4.8)$ & $6.2(2.5)$ & $3.7(2.5)$ \\
\hline & \multirow{4}{*}{ BMI } & $<18.5$ & 3 & $30.0(10.0)$ & $50.0(10.0)$ & $5.0(0.0)$ & $5.0(0.0)$ & $5.0(0.0)$ & $5.0(0.0)$ \\
\hline & & $18.5-24.9$ & 98 & $33.3(8.4)$ & $42.7(9.5)$ & $7.5(7.0)$ & $6.1(3.9)$ & $5.1(0.8)$ & $5.3(2.4)$ \\
\hline & & $25.0-29.9$ & 174 & $30.4(9.4)$ & $42.1(11.8)$ & $9.9(10.0)$ & $6.7(4.8)$ & $5.3(1.5)$ & $5.8(5.3)$ \\
\hline & & $\geq 30$ & 74 & $32.4(9.0)$ & $42.3(10.9)$ & $8.4(7.2)$ & $6.5(5.6)$ & $5.1(0.8)$ & $5.1(0.6)$ \\
\hline \multicolumn{3}{|c|}{ Oligospermia } & 349 & $32.1(9.1)$ & $43.0(10.7)$ & $8.2(8.1)$ & $6.3(4.3)$ & $5.1(1.1)$ & $5.4(3.5)$ \\
\hline \multicolumn{3}{|c|}{ Normal sperm count } & 453 & $29.9(7.4)$ & $47.8(8.9)$ & $6.4(5.0)$ & $5.6(2.5)$ & $5.0(0.6)$ & $5.2(1.7)$ \\
\hline \multicolumn{3}{|c|}{ t-test (P-value) } & & $3.96(0.00001)$ & $-7.31(0.00001)$ & $4.20(0.00001)$ & $3.12(0.0009)$ & $1.81(0.04)$ & $0.81(0.21)$ \\
\hline
\end{tabular}

in the Midpiece defect driven by age group $30-39$ year $(\mathrm{t}=-2.55$, P-value $=$ $0.006)$ and by overweight $(\mathrm{t}=-2.78$, P-value $=0.003)$ and lastly, that in the Tail defect was driven predominantly by age group $50-59$ years $(\mathrm{t}=-2.30$, $\mathrm{P}$-value $=$ $0.01)$ and overweight $(t=-2.54$, P-value $=0.006)$ (Data not shown). Also, the overall mean of oval head sperm cells of normal men $(47.8 \pm 8.9)$ was significantly higher $(\mathrm{t}=-7.31 \pm 0.00001)$ than those of oligospermic men $(43.0 \pm 10.7)$.

Multivariate regression analysis in Table 6 shows that Age and BMI explained a significant $5.12 \%$ and $3.25 \%$ respectively of the differences observed in seminal fluid volume $\left(\mathrm{R}^{2}=0.0512\right.$, P-value $\left.=0.0001\right)$ and in sperm count $\left(\mathrm{R}^{2}=0.0325\right.$, $\mathrm{P}$-value $=0.0033)$ but an insignificant explanation of the variation observed in progressive motility $\left(\mathrm{R}^{2}=0.0107\right.$, P-value $\left.=0.1560\right)$ among oligospermic patients. In this synergy between age and BMI, only age demonstrated a significant negative correlation with seminal fluid volume (Coef. $=-0.04$, Std. Err. $=0.01, t=$ $-4.05, \mathrm{P}$-value $=0.0001,95 \% \mathrm{CI}:-0.06,-0.02)$ while BMI showed a noteworthy negative correlation with sperm count (Coef. $=-0.18$, Std. Err. $=0.06, \mathrm{t}=-3.24$, 


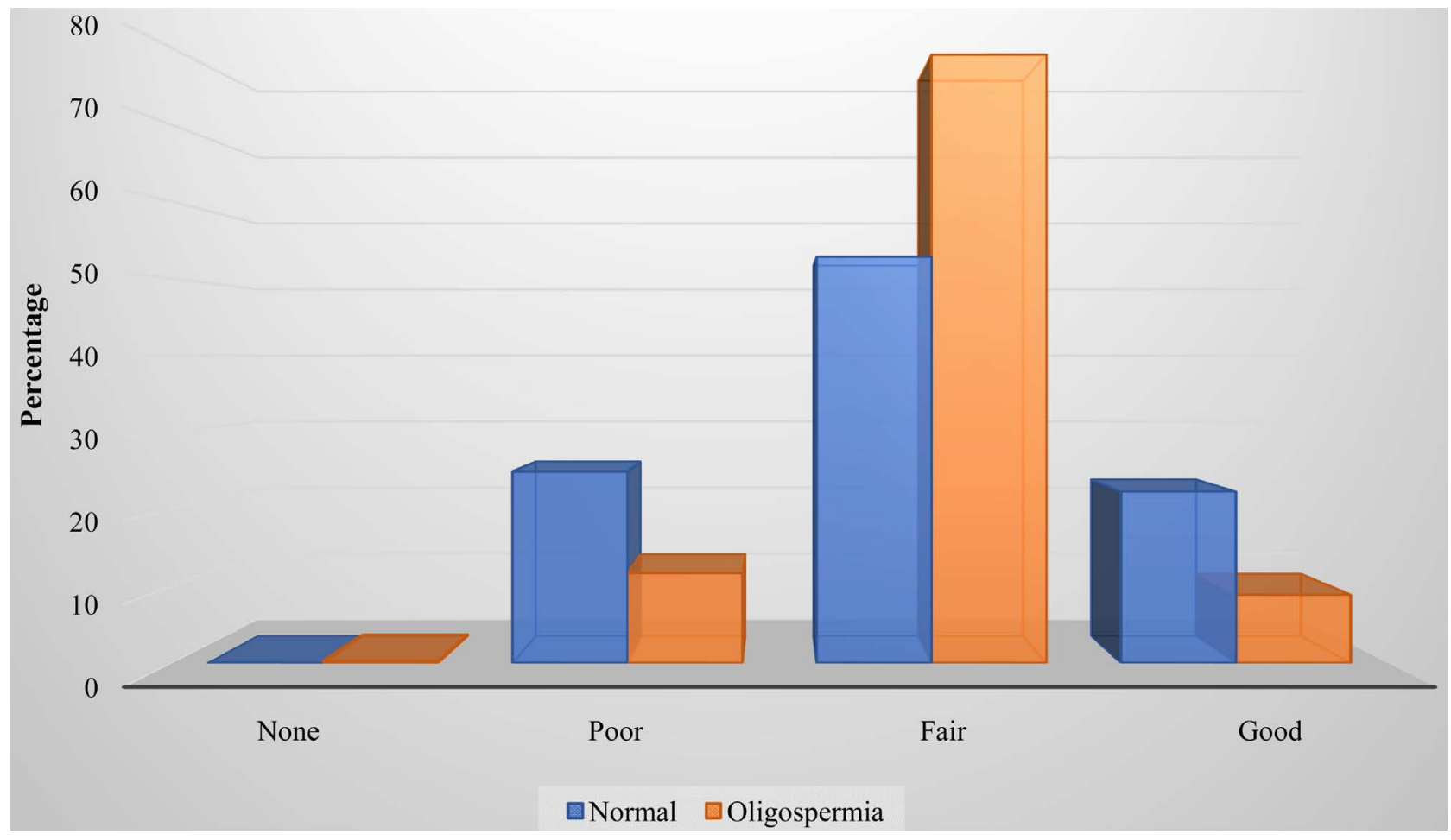

Figure 3. Percent distribution of mean progressive motion in normal and in oligospermic men in the study.

P-value $=0.001,95 \%$ CI: $-0.29,-0.07)$. Age and BMI together did not correlate with progressive motility in oligospermic patients. When BMI was removed from the synergy of Age and BMI in oligospermic group, Age gave a significant $4.43 \%$ of the alterations observed in seminal fluid volume $\left(\mathrm{R}^{2}=0.0443\right.$, $\mathrm{P}$-value $=$ 0.0001 ) and was negatively correlated with semen volume (Coef. $=-0.04$, Std. Err. $=0.01, \mathrm{t}=-4.01, \mathrm{P}$-value $=0.0001,95 \% \mathrm{CI}:-0.06,-0.02)$. The contribution of age in the explanation of variations observed in seminal fluid volume and in progressive motility was insignificant. When Age was removed from the synergy of Age and BMI in oligospermic group, BMI gave a significant $2.98 \%$ of the alterations observed in sperm count $\left(\mathrm{R}^{2}=0.0298, \mathrm{~F}\right.$-statistics $=10.65, \mathrm{P}$-value $=$ 0.001 ) and was negatively correlated with sperm count (Coef. $=-0.18$, Std. Err. = $0.06, \mathrm{t}=-3.26$, P-value $=0.001,95 \% \mathrm{CI}:-0.29,-0.07)$. The contribution of BMI to the explanation of variations observed in seminal fluid volume was insignificant and marginally noteworthy in progressive motility.

\section{Discussion}

One of the intrinsic qualities of living beings, including humans, is the continuation of the genome of each entity and reproduction is essential in carrying out this task. Those who are not able to carry out this chore of the continuation of human genome through reproduction often may be subject of ridicule from close quarters-husband, wife, families, neighbors, others-resulting in isolation, dejection, abuse, stigmatization, deprived physical, mental and social, in some cases leading to physical trauma and even death. Some studies in 
Table 6. Multivariate regression analysis with semen volume, sperm concentration and motility as dependent variables and both age and BMI, together and separately, as independent variables together.

\begin{tabular}{|c|c|c|c|c|c|c|}
\hline Equation & Obs. & $\mathbf{R}^{2}$ & $\mathbf{F}$ & $\mathrm{P}$-value & & \\
\hline Volume & & 0.0512 & 9.34 & 0.0001 & & \\
\hline Sperm count $\times 10^{6} / \mathrm{ml}$ & 349 & 0.0325 & 5.81 & 0.0033 & & \\
\hline \multirow[t]{3}{*}{ Motility } & & 0.0107 & 1.87 & 0.1560 & & \\
\hline & & Coefficient & SE & $\mathrm{t}$ & $\mathrm{P}$-value & $95 \%$ CI \\
\hline & Age & -0.04 & 0.01 & -4.05 & 0.0001 & $-0.06,-0.02$ \\
\hline \multirow[t]{3}{*}{ Volume } & BMI & -0.03 & 0.02 & -1.59 & 0.113 & $-0.06,0.01$ \\
\hline & Constant & 4.63 & 0.65 & 7.14 & 0.0001 & $3.36,5.91$ \\
\hline & Age & 0.03 & 0.03 & 0.99 & 0.324 & $-0.03,0.09$ \\
\hline \multirow[t]{3}{*}{ Sperm concentration } & BMI & -0.18 & 0.06 & -3.24 & 0.001 & $-0.29,-0.07$ \\
\hline & Constant & 9.26 & 1.98 & 4.67 & 0.000 & $5.36,13.16$ \\
\hline & Age & 0.05 & 0.13 & 0.37 & 0.713 & $-0.21,0.31$ \\
\hline \multirow[t]{2}{*}{ Motility } & BMI & -0.48 & 0.25 & -1.89 & 0.060 & $-0.98,0.02$ \\
\hline & Constant & 47.03 & 9.01 & 5.22 & 0.000 & $29.30,64.76$ \\
\hline Equation & Obs. & $\mathbf{R}^{2}$ & $\mathbf{F}$ & P-value & & \\
\hline Volume & & 0.0443 & 16.08 & 0.0001 & & \\
\hline Sperm concentration & 349 & 0.0031 & 1.07 & 0.3004 & & \\
\hline \multirow[t]{2}{*}{ Motility } & & 0.0005 & 0.16 & 0.6865 & & \\
\hline & & Coefficient & SE & $\mathbf{t}$ & $\mathrm{P}$-value & $95 \%$ CI \\
\hline \multirow{2}{*}{ Volume } & Age & -0.04 & 0.01 & -4.01 & 0.0001 & $-0.06,-0.02$ \\
\hline & Constant & 3.83 & 0.41 & 9.32 & 0.000 & $3.02,4.64$ \\
\hline \multirow{2}{*}{ Sperm concentration } & Age & 0.03 & 0.03 & 1.04 & 0.300 & $-0.03,0.09$ \\
\hline & Constant & 4.28 & 1.27 & 3.36 & 0.001 & $1.77,6.78$ \\
\hline \multirow{2}{*}{ Motility } & Age & 0.05 & 0.13 & 0.40 & 0.687 & $-0.21,0.31$ \\
\hline & Constant & 33.84 & 5.72 & 5.91 & 0.000 & $22.58,45.10$ \\
\hline Equation & Obs. & $\mathbf{R}^{2}$ & $\mathbf{F}$ & $\mathrm{P}$-value & & \\
\hline Volume & & 0.0062 & 2.18 & 0.141 & & \\
\hline Sperm concentration & 349 & 0.0298 & 10.65 & 0.001 & & \\
\hline \multirow[t]{2}{*}{ Motility } & & 0.0103 & 3.61 & 0.058 & & \\
\hline & & Coefficient & SE & $\mathrm{t}$ & $\mathrm{P}$-value & $95 \%$ CI \\
\hline \multirow{2}{*}{ Volume } & BMI & -0.03 & 0.02 & -1.48 & 0.141 & $-0.06,0.01$ \\
\hline & Constant & 2.95 & 0.51 & 5.79 & 0.000 & $1.95,3.96$ \\
\hline \multirow{2}{*}{ Sperm concentration } & BMI & -0.18 & 0.06 & -3.26 & 0.001 & $-0.29,-0.07$ \\
\hline & Constant & 10.51 & 1.52 & 6.89 & 0.000 & $7.51,13.51$ \\
\hline \multirow{2}{*}{ Motility } & BMI & -0.48 & 0.25 & -1.90 & 0.058 & $-0.98,0.02$ \\
\hline & Constant & 49.15 & 6.92 & 7.10 & 0.000 & $35.53,62.76$ \\
\hline
\end{tabular}

sub-Saharan Africa have given account of disorders of the reproductive system in males and females of reproductive age with variable results, especially in the males. That Clinicians are responsible for the sexual health of males needs to inform men 
with mild, moderate or severe oligospermia that this condition may be as a result abnormality in their chromosomes. Clinicians should then attempt to identify such abnormality through laboratory tests and correct it as much as possible.

This study analyzed the biophysical characteristics of infertile men who were given laboratory diagnosis of oligospermia and who sought for Assisted Reproduction Technology at the Nordica Fertility Center in Nigeria. The first key finding in this study is that majority of the patients were aged $40-49$ years, an older age range than the 30 years and above reported from Ghana [21] or the 35.8 years reported from Tanzania [18]. This finding suggests that oligospermia may occur at older age in Nigeria than in other African countries where it occurs at a younger age. The fact that oligospermia possibly occurs in older age among Nigerians may be responsible for its large population with its consequences on infrastructures, education, housing and environmental degradation.

Another key finding is that a high proportion of these patients were overweight. Body Mass Index (BMI) of fertile and infertile men have been studied extensively. Some studies have shown that higher BMI is associated with impaired semen parameters, and others have shown improvement in semen parameters with weight loss [29]. This study reports that of the 802 participants, 553 (69.1\%) were overweight (408) and obese (145); figures that were much lower than the $72.8 \%$ combined overweight and obese patients in a similar study in New Zealand [29]. Of the 408 men who were overweight in this study, 174 (42.6\%) presented with oligospermia, similar to the $41 \%$ reported by Eisenberg et al. [30]. Overall, age alone or BMI alone may not significantly contribute to seminal fluid volume as indicated in this study which agrees with what Schwartz [31] earlier reported. But when age was segregated, a significant difference was shown in the seminal fluid volume of normal and of oligospermic patients only at age 50 - 59 years. Earlier studies did not separate the patients into normospermic, oligospermic and azoospermic patients in considering the effects of age on seminal fluid volume.

A relative high proportion of patients in this study, as in other studies [17] [32] [33] [34] [35], reported with oligospermia which predisposes them to higher risk of developing both testicular cancer and prostate cancer later in life [25]. Therefore, oligospermia may be regarded as an accepted biomarker of imminentmale health problems.

At first glance, there was no significant difference in the mean liquefaction time ( $\mathrm{min}$ ) but when examined according to different categories of age and BMI; it became apparent that there were significant differences in liquefaction time at some different age groups and different BMI, especially in obese patients. Cui et al. [36] reported a significant longer semen liquefaction time in patients with Anti-sperm antibodies than in their control group, indicating a negative effect of ASA on liquefaction time. Longer liquefaction prevents timely availability of viable sperm cells for fertilization of accessible egg which may be problematic for patients with advanced age and those who are overweight.

In contrast to normal patients, a high proportion of patients with oligosper- 
mia presented with $\mathrm{PM}$ of $<32 \%$, especially in younger age group of $<40$ years and in obese patients, a situation that was reversed in older age group till $<60$ years and normal BMI. One of the consequences of low progressive sperm motility is inability of the sperm cells to swim forward in the female genital tract and reach the egg on time for fertilization to take place. It is possible that, as reported in a recent study [37], patients who presented with asthenozoospermia in our study also demonstrated high basal and stimulated reactive oxygen species (ROS) production with increased mitochondrial DNA (mtDNA) copy number but decreased mtDNA integrity associated with elevated ROS levels. Another study reported that aneuploidy is associated with low progressive sperm motility [38]. This paper reports a mean of $32.1( \pm 9.1)$ concentration of small tapering head abnormal sperm cells among oligospermic patients compared to 29.9 $( \pm 7.4)$ of such cells among men with normal sperm count, with a highly significant statistical difference between the two. On the other hand, patients with oligospermia had a highly significant lower concentration of normal oval head sperms compared to those with normal sperm count. This finding aligns with the report from a Nigerian study which documented a statistically significant higher abnormal morphology ( $81 \%$ vs. $67 \%, \mathrm{P}=0.01)$ among oligospermic patients compared to those with normospermia [39].

Complete non-motile sperm cells were rare in this study, occurring on only one patient aged 40 - 49 years who was also overweight. This agrees with what Ortega et al., [40] reported in their study that complete as the nozoospermia occurred at a frequency of 1 of 5000 men. More than half of the oligospermic patients with poor mean progressive motion were aged 40 - 49 years with BMI of 25 - 29.9 Very few (8.9\%) proportion of oligospermic patients had sperms with good Mean Progressive Motion or Grade 4 movement, especially those aged 30 39 years and with BMI of $25-29.9 \mathrm{~kg} / \mathrm{m}^{2}$. Progression refers to the forward movement of sperm and is recorded as: Grade 4: Fast and forward progression where sperm move in a straight direction. Several studies support the importance of the mitochondria in maintaining sperm quality and motility; in fact, as the nozoospermia [41] and oligoasthenozoospermia [42] have been reported in patients with typical mitochondrial diseases characterized by point mutations or multiple deletions in mtDNA.

Oligospermic patients had significant sperm cell defects compared to those with normal sperm count. The argument that reactive oxygen species (ROS) production is involved in the pathogenesis of sperm abnormalities may be valid also for oligospermia and defects in sperm morphology. A study reported high proportion of patients with severe asthenozoospermia who showed increased basal and stimulated ROS production and also demonstrated increased mitochondrial DNA (mtDNA) copy number but decreased mtDNA integrity and they were associated with elevated ROS levels [37].

\section{Conclusion}

In conclusion, biological and statistical data from the present research support 
the idea that oligospermia could be associated with transformation of sperm morphology, reduced progressive motility, mean progressive motion as well as with reduced liquefaction time, especially when biophysical properties of the patients such as age and Body Mass Index are segregated. Otherwise, merely reporting the observation without segregation of the two variables of age and BMI may give a false positive or a false negative. For example, though there appeared to be no significant difference in the liquefaction time (min.) between patients with normal sperm count and those with oligospermia, on segregation of BMI it was found that there was a significant difference in the liquefaction time of normal patients who were obese and oligospermic men who were obese.

\section{Strengths and Limitations}

\subsection{Strength}

1) Semen collection was strictly adhered to.

2) Anthropometric data of patients were recorded at consultation, not volunteered by patients.

3) Up-to-date laboratory equipment was used for semen analysis and in almost all cases each analysis was on two consecutive samples.

4) Enough number of overweight and obese patients was available for the study.

5) The same study criteria were used for all the patients.

\subsection{Weaknesses}

1) This was a facility-based study limiting generalizability of the findings. A more robust study including the community is urgently needed.

2) Semen parameters may not be completely accurate measures to determine fertility. This study examined only oligospermia but not pregnancy success rates among oligospermic patients. Therefore, it is not certain how the findings relate to infertility per se in our setting.

\section{Authors' Contribution}

ABA conceived of the study, participated in its design, and helped to draft the manuscript. BMA participated in its design, performed the statistical analysis, and drafted the manuscript. VDA, IO and AA handled the recruitment of patients, sample collection, and supervised the clinical aspects of the work. AA supervised all laboratory work. All authors read and approved the final manuscript.

\section{Funding Organization}

None.

\section{Conflicts of Interest}

All authors declare no competing interests. 


\section{References}

[1] Naina Kumar, N., Singh, A.K. (2015) Trends of Male Factor Infertility, an Important Cause of Infertility: A Review of Literature. Journal of Human Reproductive Sciences, 8, 191-196. https://doi.org/10.4103/0974-1208.170370

[2] Zegers-Hochschild, F., Adamson, G.D., de Mouzon, J., Ishihara, O., Mansour, R., Nygren, K., et al. (2009) International Committee for Monitoring Assisted Reproductive Technology (ICMART) and the World Health Organization (WHO) Revised Glossary of ART Terminology, 2009. Fertility and Sterility, 92, 1520-1524. https://doi.org/10.1016/j.fertnstert.2009.09.009

[3] Duncan, J.M. (1998) Fecundity, Fertility and Sterility. Human Reproduction, 13, 33-44.

[4] Templeton, A., Morris, J.K. and Parslow, W. (1996) Factors That Affect Outcome of in-Vitro Fertilisation Treatment. The Lancet, 348, 1402-1406.

https://doi.org/10.1016/S0140-6736(96)05291-9

[5] Templeton, A.A. (1992) The Epidemiology of Infertility. In: Templeton, A.A. and Drife, J.O., Eds., Infertility, Springer-Verlag, Berlin, 23-34. https://doi.org/10.1007/978-1-4471-1962-3_2

[6] Greenhall, E. and Vessey, M. (1990) The Prevalence of Subfertility: A Review of the Current Confusion and a Report of Two New Studies. Fertility and Sterility, 54, 978-983. https://doi.org/10.1016/S0015-0282(16)53990-9

[7] Thonneau, P. and Spira, A. (1990) Prevalence of Infertility: International Data and Problems of Measurement. European Journal of Obstetrics \& Gynecology and Reproductive Biology, 38, 43-52. https://doi.org/10.1016/0028-2243(91)90206-Z

[8] Mosher, W.D. and Pratt, W.F. (1991) Fecundity and Infertility in the United States: Incidence and Trends. Fertility and Sterility, 56, 192-193.

https://doi.org/10.1016/S0015-0282(16)54469-0

[9] Inhorn, M.C. and Patrizio, P. (2015) Infertility around the Globe: New Thinking on Gender, Reproductive Technologies and Global Movements in the 21st Century. Human Reproduction Update, 21, 411-426.

https://doi.org/10.1093/humupd/dmv016

[10] World Health Organization (2010) WHO Laboratory Manual for the Examination and Processing of Human Semen. 5th Edition, World Health Organization, Geneva.

[11] Chan, P. Clinical Male Infertility: Epidemiology and Basic Evaluation. Handbook of Andrology. https://andrologysociety.org/getattachment/c62d64c1-8a4c-4a32

[12] Leke, R.J., Oduma, J.A., Bassol-Mayagoitia, S., Bacha, A.M. and Grigor, K.M. (1993) Regional and Geographical Variations in Infertility: Effects of Environmental, Cultural, and Socioeconomic Factors. Environmental Health Perspectives, 101, 73-80. https://doi.org/10.1289/ehp.93101s273

[13] Fisch, H. and Goluboff, E.T. (1996) Geographic Variations in Sperm Counts: A Potential Cause of Bias in Studies of Semen Quality. Fertility and Sterility, 65, 1009-1114. https://doi.org/10.1016/S0015-0282(16)58278-8

[14] Auger, J. and Jouannet, P. (1997) Evidence for Regional Differences of Semen Quality among Fertile French Men. Federation Francaise des Centres d'Etude et de Conservation des Oeufs et du Sperme humains. Human Reproduction, 12, 740-745. https://doi.org/10.1093/humrep/12.4.740

[15] Jorgensen, N., Andersen, A.G., Eustache, F., Irvine, D.S., Suominen, J., Petersen, J.H., et al. (2001) Regional Differences in Semen Quality in Europe. Human Reproduction, 16, 1012-1019. https://doi.org/10.1093/humrep/16.5.1012 
[16] Costabile, R.A. and Spevak, M. (2001) Characterization of Patients Presenting with Male Factor Infertility in an Equal Access, no Cost Medical System. Urology, 58, 1021-1024. https://doi.org/10.1016/S0090-4295(01)01400-5

[17] Irfan, M., Shabbir, A., Raja, G.K., Kiyani, A.R. and Ismail, M. (2015) Sperm Disorders and Aetiologies of Male Infertility in Pakistan: Meta-Analyses and Review. Austin Journal of Reproductive Medicine \& Infertility, 2, 1034.

[18] Larsen, U., Masenga, G. and Mlay, J. (2006) Infertility in a Community and Clinic-Based Sample of Couples in Moshi, Northern Tanzania. East African Medical Journal, 83, 10-17. https://doi.org/10.4314/eamj.v83i1.9355

[19] Owolabi, A.T., Fasuba, O.B. and Ogunniyi, S.O. (2013) Semen Quality of Male Partners of Infertile Couples in Ile-Ife, Nigeria. Nigerian Journal of Clinical Practice, 16, 37-40. https://doi.org/10.4103/1119-3077.106729

[20] Ikechebula, J.I., Adinma, J.I., Orie, E.F. and Ikegwuonu, S.O. (2003) High Prevalence of Male Infertility in Southeastern Nigeria. Journal of Obstetrics and Gynaecology, 6, 657-659. https://doi.org/10.1080/01443610310001604475

[21] Opoku, A., Boateng, D., Quansah, D.Y., Bedu-Addo, K. and Ankobea-Krokoe, F. (2014) Semen Characteristics of Male Infertile Couples in the Kumasi Metropolis: A Study of Primary and Secondary Infertile Couples. British Journal of Medicine \& Medical Research, 4, 1432-1441. https://doi.org/10.9734/BJMMR/2014/5700

[22] Yoshida, A., Miura, K., Nagao, K., et al. (1997) Sexual Function and Clinical Features of Patients with Klinefelter's Syndrome with the Chief Complaint of Male Infertility. International Journal of Andrology, 20, 80-85. https://doi.org/10.1046/j.1365-2605.1997.00109.x

[23] Yatsenko, A.N., Yatsenko, S.A., et al. (2010) Comprehensive 5-Year Study of Cytogenetic Aberrations in 668 Infertile Men. Journal of Urology, 183, 1636-1642. https://doi.org/10.1016/j.juro.2009.12.004

[24] Porter, R.S. and Kaplan, J.L. (2011) Merck Manual of Diagnosis and Therapy. 19th Edition, Merck Sharp \& Dohme Corp, Whitehouse Station, NJ.

[25] http://www.theturekclinic.com/services/male-fertility-specialist-specialists-infertilit y-doctor-treatments-issues-zero-sperm-count-male-doctors-male-fertility-clinics/ol igospermia-low-sperm-count-semen-analysis-0-rare-definition-what/

[26] Plachot, M., Belaisch-Allart, J., Mayenga, J., Chouraqui, A., Tesquier, L. and Serkine, A. (2002) Outcome of Conventional IVF and ICSI on Sibling Oocytes in Mild Factor Infertility. Human Reproduction, 17, 362-369. https://doi.org/10.1093/humrep/17.2.362

[27] Ajayi, A.B., Afolabi, B.M., Ajayi, V.D., Oyetunji, I., Biobaku, O. and Atiba, A. (2018) Men without Sperms. Open Journal of Urology, 8, 25-42. https://doi.org/10.4236/oju.2018.81004

[28] WHO (2018) BMI Classification. http://www.who.int/gho/ncd/risk_factors/bmi_text/en/

[29] Macdonald, A.A., Stewart, A.W. and Farquhar, C.M. (2013) Body Mass Index in Relation to Semen Quality and Reproductive Hormones in New Zealand Men: A Cross-Sectional Study in Fertility Clinics. Human Reproduction, 28, 3178-3187. https://doi.org/10.1093/humrep/det379

[30] Eisenberg, M.L., Kim, S., Chen, Z., et al. (2014) The Relationship between Male BMI and Waist Circumference on Semen Quality: Data from the LIFE Study. Human Reproduction, 29, 193-200. https://doi.org/10.1093/humrep/det428

[31] Schwartz, D., Mayaux, M.J., Spira, A., Moscato, M.L., Jouannet, P., Czyglik, F. and 
David, G. (1983) Semen Characteristics as a Function of Age in 833 Fertile Men. Fertility and Sterility, 39, 530-535. https://doi.org/10.1016/S0015-0282(16)46946-3

[32] Abarikwu, S.O. (2013) Causes and Risk Factors for Male-Factor Infertility in Nigeria: A Review. African Journal of Reproductive Health, 17, 150-166.

[33] Kumar, N., Choudhari, A.R. and Singh, A.K. (2015) Prevalence of Male Factor Infertility in Last Ten Years at a Rural Tertiary Care Centre of Central India: A Retrospective Analysis. Indian Journal of Obstetrics and Gynaecology Research, 2, 132-136. https://doi.org/10.5958/2394-2754.2015.00002.8

[34] Ahmadi, M.R.H., Yasemi, M., Peyman, H., Hemati, K., Khajavikhan, J., Yaghoubi, M. and Bimanand, L. (2014) Prevalence and Risk Factors of Oligospermia in Infertile Men. Journal of Clinical and Diagnostic Research, 8, FC11-FC13.

[35] Ajayi, R.A., Parsons, J.H. and Bolton, V.N. (2003) Live Births after Intracytoplasmic Sperm Injection in the Management of Oligospermia and Azoospermia in Nigeria. African Journal of Reproductive Health, 7, 121-124. https://doi.org/10.2307/3583352

[36] Cui, D., Han, G., Shang, Y., Liu, C., Xia, L., Li, L. and Yi, S. (2015) Antisperm Antibodies in Infertile Men and Their Effect on Semen Parameters: A Systematic Review and Meta-Analysis. Clinica Chimica Acta, 444, 29-36. https://doi.org/10.1016/j.cca.2015.01.033

[37] Bonanno, O., Romeo, G., Asero, P., Pezzino, F.M., Castiglione, R., Burrello, N., Sidoti, G., Frajese, G.V., Vicari, E. and D’Agata, R. (2016) Sperm of Patients with Severe Asthenozoospermia Show Biochemical, Molecular and Genomic Alterations. Reproduction, 152, 695-704. https://doi.org/10.1530/REP-16-0342

[38] Collodel, G., Capitani, S., Baccetti, B., Pammolli, A. and Moretti E. (2007) Sperm Aneuploidies and Low Progressive Motility. Human Reproduction, 22, 1893-1898. https://doi.org/10.1093/humrep/dem099

[39] Ugwuja, E.I., Ugwu, N.C. and Ejikeme, B.N. (2008) Prevalence of Low Sperm Count and Abnormal Semen Parameters in Male Partners of Women Consulting at Infertility Clinic in Abakaliki, Nigeria. African Journal of Reproductive Health, 12, 67-73.

[40] Ortega, C., Verheyen, G., Raick, D., Camus, M., Devroey, P. and Tournaye, H. (2011) Absolute Asthenozoospermia and ICSI: What Are the Options? Human Reproduction, 17, 684-692.

[41] Folgero, T., Bertheussen, K., Lindal, S., Torbergsen, T. and Oian, P. (1993) Mitochondrial Disease and Reduced Sperm Motility. Human Reproduction, 8, 1863-1868. https://doi.org/10.1093/oxfordjournals.humrep.a137950

[42] Lestienne, P., Reynier, P., Chretien, M.F., Pennisson-Besnier, I., Malthiery, Y. and Rohmer, V. (1997) Oligoasthenospermia Associated with Multiple Mitochondrial DNA Rearrangements. Molecular Human Reproduction, 3, 811-814. https://doi.org/10.1093/molehr/3.9.811 